analysis employed by these authors did not provide 'a precise assessment of the effect of diabetic duration on lens biometry.' In terms of the diabetic subgroup the only similarity in the findings of these two studies was that they both demonstrated diabetic duration to be relevant to lens thickness.

JOHN M SPARROW Department of Ophthalmology, University of Leicester, Leicester Royal Infirmary Leicester LE $15 W W$

1 Sparrow JM, Bron AJ, Brown NAP, Neil HAW. Biometry of the crystalline lens in early-onset diabetes. Br f Ophthalmol 1990; 74: 654-60.

2 Fledelius HC, Miyamoto K. Diabetic myopia - Is it lens induced? An oculometric study comprising ultrasound measurements. Acta Ophthalmol (Kbh) 1987; 65: 469-73.

\section{Hold-up of fluorescein in the arm}

SIR, - A potentially common cause of early arterial phase fluorescein angiographic delay is reported. A fit 36-year-old draughtsman with unilateral paracentral visual distortion of six months' duration and bilateral macular retinal pigment epithelial changes was investigated by fluorescein angiography. $5 \mathrm{ml}$ of $20 \%$ sodium fluorescein was injected by 21 gauge 'butterfly' into a dorsal hand vein, followed by $4 \mathrm{ml}$ washthrough of $0.9 \%$ saline. No dye appeared in the retinal arterioles. The injected (upper) arm, resting on the fundus camera handlebar (forearm pronated), became uncomfortable above the elbow medially. This eased on lifting the limb. Fluorescein entered the retinal vessels 10 seconds thereafter (arm-retina circulation time'), 117 seconds after initial intravenous injection. The delay was caused by the tourniquet effect of the camera handlebar.

The dorsal veins of the hand drain medially into the basilic vein and laterally into the cephalic vein, which may drain almost entirely into the basilic by a median vein in the cubital fossa. ${ }^{2}$ Pressure on the medial upper arm in such individuals will slow venous drainage from the limb - not so if the proximal cephalic vein is larger.

In this patient the bolus effect was reduced, making identification of treatable leaking spots more difficult in the early phase angiograms. Upper limb position and support (previously described for antecubital injection) $)^{3}$ must be considered during fluorescein angiography L G KAYE-WILSON

Princess Alexandra Eye Pavilion, Chalmers Street, EH39HA

David NJ, Saito Y, Heyman A. Diagnosis of carotid artery occlusion by arm to retina fluorescein appearance time. Arch Neurol 1961; 5: 165-70.

Williams PL, Warwick R, Dyson M, Banniste LH, eds. Gray's anatomy. Edinburgh: Churchill Livingstone, 1989: 806-7.

3 Rubinstein K. Arm-rest for fluorescein photography. Brf Ophthalmol 1968; 52: 864.

\section{BOOK REVIEWS}

Ophthalmology: What Shall I Do? By Jack J Kanski, Bev Daily. Pp 71. £5.95. Butterworth: Guildford, Surrey. 1989.

This slim book was written for general practitioners. It is the second in a series co-authored by Dr Daily (the other covering neurology) and a very good buy at £5.95. Mr Kanski is well known for his books on many aspects of ophthalmology, all notable for their easily read text and high standards of production.

The text is set out as questions which are then answered in language which general practitioners will understand. The authors cover all common conditions such as senile macular degeneration, glaucoma, and cataract. In addition there are useful sections on less obvious topics such as visual standards and blind registration. There is a two-page display at the end entitled 'When to refer and to whom.' This sets out the rapidity of referral indicated for various conditions. The text is well set out on the pages, easily read, and impressively free of spelling mistakes. Illustrations are used sparingly but effectively.

The ophthalmic content is of a high standard. The text represents a distillation of modern views on clinical management of ophthalmic problems. There are a few points which ophthalmologists might be interested to discuss among themselves. For example, the reader is advised to remove a metal foreign body from the cornea in the surgery and clear the rust ring. Some may consider this unnecessarily exciting without the magnification of the slit-lamp. General practice elements are well covered - for example, the relationship between timolol and asthma, and the need for ophthalmologists to visualise senile macular changes before advising whether cataract surgery would be helpful. The index was particularly helpful in tracking items down.

This book really succeeds in two areas. First, it is short. This should encourage the potential reader to pick it up. The whole thing could be read in 10 minutes a day over seven days. Second, it offers solutions to problems general practitioners face during their daily work and is therefore much more 'user friendly' than a short textbook. The answers to clinical problems are given at a level which should not frighten anyone. A general practitioner who has struggled with conventional texts would probably find a few minutes with this book most enlightening. In conclusion we strongly recommend it for general practitioners.

\section{JOHN BRAZIER} ROY MACGREGOR

Binocular Vision and Ocular Motility: Theory and Management of Strabismus. 4th Edn. By Gunter K von Noorden. Pp 557. £78. Mosby: Baltimore, 1990.

I am glad to welcome the latest edition of this classic textbook, the previous third edition having been published in 1985. Some changes have inevitably taken place. The title is no longer 'Burian and von Noorden's . . .', it is now entirely under the name of Professor von Noorden, but to make up for this there is now a picture of Dr Burian on the inside of the book, whereas previously we just had his name.

The third edition had 500 pages and 498 illustrations and the fourth edition has 557 pages with 504 illustrations. The main changes are that the chapter on neuroanatomy has been dropped, as the author feels that it is now impossible to give an adequate discussion of this subject in a book of this size and refers us very properly to Miller's edition of Walsh and Hoyt's textbook. To counterbalance this the chapter on sensory signs, symptoms, and adaptations has been substantially increased from 72 to 85 pages, and this is a considerable benefit, as many textbooks do not go into as much detail in this area. In addition Professor von Noorden's recent interest in nystagmus is clearly reflected in the much enlarged section in the newer textbook.

I am glad to notice that Professor von Noorden now regards botulinum toxin injections as an adequate method of treatment of certain conditions, though he still seems to have his doubts as to its general applicability.

The surgical section has been reorganised, with new illustrations drawn by Rudolph Branner. I have to confess to a preference for the old illustrations. The Branner series, in my view, is too detailed and tends to have become much busier with many more pictures. For instance, in the previous edition it was possible to illustrate a rectus muscle resection in six pictures, though many of us would think that fewer would be adequate. The sequence now runs to 15 pictures, including pictures of the conjunctiva being sewn up. This seems to me an overabundance of visual material. Similar objections could be raised to all the other series of the surgical section of the book, and this is, I think, a retrograde step, though perhaps in or North America it is of great value to show everything in a step-by-step fashion for the occasional surgeon.

I am glad to notice that the index now refers to anomalous correspondence and not anomalous retinal correspondence but puzzled as to why there are two page references to 'ailerons' in the index. My dictionary defines these as devices for turning aeroplanes around, and I can find no actual reference to the word on the page to which we are referred.

In conclusion, however, I would emphasise that this is still in my view the very best single textbook on ocular motility and strabismus and that the chapter modifications are very much to its advantage. With the few quibbles about illustrations, this is yet again the book to be recommended to all persons with an interest in this area.

JOHN LEE

Glaucoma: A Colour Manual of Diagnosis and Treatment. By Jack J Kanski, James A McAllister. Pp 152. £45. Butterworth: Guildford, Surrey. 1989.

The ophthalmic subspecialties have given birth to a pantheon of learned texts, each filling a niche in the perceived requirements of the reading public. Some appear as atlases, others ? as multiauthored tomes held together by the editor, while others appear as the result of superhuman endeavour by a single author aiming to stamp his own personality on to his chosen field. Each of these 'types' share in common the central core of the subspecialty, embellished according to the author's perception of the niche to be filled. It is this core that Kanski and McAllister have captured.

In this slim volume, written in a clarity of style which the senior author has made his own, is summarised with admirable simplicity the whole of the subspecialty. Each chapter is well illustrated, with note form presentation of information and clinical pearls boxed for extra emphasis. A short bibliography for further reading is available for the curious. The book forms an admirable launch pad for the tyro and a worthwhile text for the paramedic. It is a text which any practitioner in the field would be proud to have produced but few could have achieved. . .

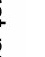

